\title{
Emission Mössbauer Spectroscopy study of fluence dependence of paramagnetic relaxation in $\mathrm{Mn} / \mathrm{Fe}$ implanted $\mathrm{ZnO}$
}

\author{
H. Masenda ${ }^{\mathrm{a} *}$, S. Geburt ${ }^{\mathrm{b}}$, K. Bharuth-Ram ${ }^{\mathrm{c}}$, D. Naidoo ${ }^{\mathrm{a}}$, H. P. Gunnlaugsson ${ }^{\mathrm{d}}$, \\ K. Johnston ${ }^{d}$, R. Mantovan ${ }^{\text {e }}$ T. E. Mølholt ${ }^{d}$, M. Ncube ${ }^{a}$, S. Shayestehaminzadeh ${ }^{f}$ \\ H. P. Gislason ${ }^{\mathrm{g}}$, G. Langouche ${ }^{\mathrm{h}}$, S. Ólafsson ${ }^{\mathrm{g}}$, C. Ronning ${ }^{\mathrm{b}}$ and ISOLDE Collaboration
}

${ }^{a}$ School of Physics, University of the Witwatersrand, Johannesburg, 2050, South Africa,

bInstitue of Solid State Physics, University of Jena, 07743, Jena, Germany

${ }^{c}$ Physics Department, Durban University of Technology, Durban 4001, South Africa,

${ }^{\mathrm{d}}$ PH Dept, ISOLDE/CERN, 1211 Geneva 23, Switzerland,

${ }^{\mathrm{e}}$ Laboratorio MDM, IMM-CNR, Via Olivetti 2, 20864 Agrate Brianza (MB), Italy,

${ }^{\mathrm{f}}$ Institute of Materials Chemistry, RWTH Aachen University, Kopernikusstr. 10, 52074 Aachen, Germany

${ }^{\mathrm{g}}$ Science Institute, University of Iceland, Dunhaga 3,107 Reykjavík, Iceland,

${ }^{\mathrm{h}}$ KULeuven, Instituut voor Kern-en Stralingsfysica, 3001 Leuven, Belgium,

\begin{abstract}
Emission Mössbauer Spectroscopy following the implantation of radioactive precursor isotope ${ }^{57} \mathrm{Mn}^{*}\left(t_{1 / 2}=1.5 \mathrm{~min}\right)$ at ISOLDE/CERN show that a large fraction of ${ }^{57} \mathrm{Fe}$ atoms produced in the ${ }^{57} \mathrm{Mn}$ beta decay are trapped as paramagnetic $\mathrm{Fe}^{3+}$ with relatively long spin-lattice relaxation times in $\mathrm{ZnO}$. We have extended this study to eMS studies on $\mathrm{ZnO}$ pre-implanted with ${ }^{56} \mathrm{Fe}$ to fluences of $2 \times 10^{13}, 5 \times 10^{13}$ and $8 \times 10^{13}$ ions $/ \mathrm{cm}^{2}$, in order to investigate the dependence of the paramagnetic relaxation rate with fluence. The spectra in the present samples are also dominated by magnetic features displaying paramagnetic relaxation effects. The extracted spin-lattice relaxation rates show a slight increase with increasing ion fluence at corresponding temperatures and the area fraction of $\mathrm{Fe}^{3+}$ at room temperature reach a maximum contribution in studied fluence range.
\end{abstract}

Keywords: ZnO, Fe implantation, emission Mössbauer spectroscopy, spin-lattice relaxation

*Contact author: hilary.masenda@wits.ac.za 


\section{Introduction}

In the midst of many reports with mixed conclusions on the nature of magnetism in Fe doped $\mathrm{ZnO}[1,2,3,4,5,6,7]$, we have reported results of emission Mössbauer spectroscopy (eMS) on virgin $\mathrm{ZnO}$ single crystals following ${ }^{57} \mathrm{Mn}^{+}$implantation with a fluence of $\sim 3 \times 10^{12}$ ions $/ \mathrm{cm}^{2}[8$, 9] and over a wide range of ion fluence [10]. The absence of ordered magnetism (above $90 \mathrm{~K}$ ) in extremely dilute doped $\mathrm{ZnO}$ was unequivocally proven through angle dependent eMS measurements in the presence of an external magnetic field of $0.6 \mathrm{~T}$ [8]. The emission Mössbauer spectra exhibited paramagnetism, resulting from $\mathrm{Fe}^{3+}$ located on $\mathrm{Zn}$ substitutional sites weakly coupled to the lattice and showing temperature dependent spin-lattice relaxation. The $\mathrm{Fe}^{3+}$ spin-lattice relaxation rate was found to follow an unusual $T^{9}$ temperature dependence [9].

Moreover, we have conducted eMS and X-ray Magnetic Circular Dichroism (XMCD) studies [10] on the effect of fluence (increase in $3 d$-atoms concentration) on the magnetic contribution in $\mathrm{ZnO}$ samples implanted with Fe with atomic concentrations in two regimes, $0.1-6.4 \times 10^{-4}$ at.\% and $0.02-2.2$ at.\%. In the latter concentration range, a transition to spin-spin relaxation effects between neighbouring $\mathrm{Fe}^{3+}$ ions was observed from the spin-lattice relaxation observed at the lower concentration regime. In this paper, we focus on the magnetic contribution and on spin-lattice relaxation in $\mathrm{ZnO}$ crystals implanted with $\mathrm{Fe}$ with atomic concentrations in the range $0.49 \times 10^{-2}-1.97 \times 10^{-2}$ at. $\%$, which cover the upper intermediate region of atomic concentration not reported in similar previous studies [10].

\section{Experimental Details}

Commercially acquired $\mathrm{ZnO}$ single crystals (Crystec $\mathrm{GmbH})$ were implanted with ${ }^{56} \mathrm{Fe}$ ions using a multipurpose ion implanter, with implantation energy of $60 \mathrm{keV}$ and at an angle of $7^{\circ}$ to avoid channelling effects. Three $\mathrm{ZnO}$ samples were pre-implanted with ${ }^{56} \mathrm{Fe}$ ions to fluences of $2 \times 10^{13}, 5 \times 10^{13}$ and $8 \times 10^{13}$ ions $/ \mathrm{cm}^{2}$. The corresponding atomic concentrations integrated over the ${ }^{57} \mathrm{Mn}$ profile are $0.49 \times 10^{-2}, 1.23 \times 10^{-2}$ and $1.97 \times 10^{-2}$ at. $\%$, respectively.

${ }^{57} \mathrm{Fe}$ eMS measurements were conducted utilising implantation of radioactive ${ }^{57} \mathrm{Mn}^{+}$ions $\left(T_{1 / 2}\right.$ $=1.5 \mathrm{~min}$ ) at the ISOLDE facility at CERN . The beam is produced by $1.4 \mathrm{GeV}$ proton- induced fission in an $\mathrm{UC}_{2}$ target and multi-stage subsequent laser ionization. Pure beams with intensities $\leq 5 \times 10^{8}$ ions/s and $40 \mathrm{keV}$ energy were implanted at $30^{\circ}$ relative to the sample normal into the $\mathrm{ZnO}$ single crystals held at temperatures ranging from room temperature to $570 \mathrm{~K}$. eMS spectra were measured using a parallel plate avalanche detector equipped with a ${ }^{57} \mathrm{Fe}$ enriched stainless 
steel electrode, mounted on a conventional drive system outside the implantation chamber at $60^{\circ}$ relative to the sample normal. Isomer shifts and velocities are given relative to the centre of the spectrum of $\alpha-\mathrm{Fe}$ at room temperature.

\section{Analysis and results}

The emission Mössbauer spectra obtained for the $8 \times 10^{13}\left(\mathrm{ZnO}:{ }^{56} \mathrm{Fe} 8\right)$ and $5 \times 10^{13}$ ions $/ \mathrm{cm}^{2}$ $\left(\mathrm{ZnO}:{ }^{56} \mathrm{Fe} 5\right)$ pre-implanted $\mathrm{ZnO}$ samples, together with the fitted spectral components, are shown in Figure 1.
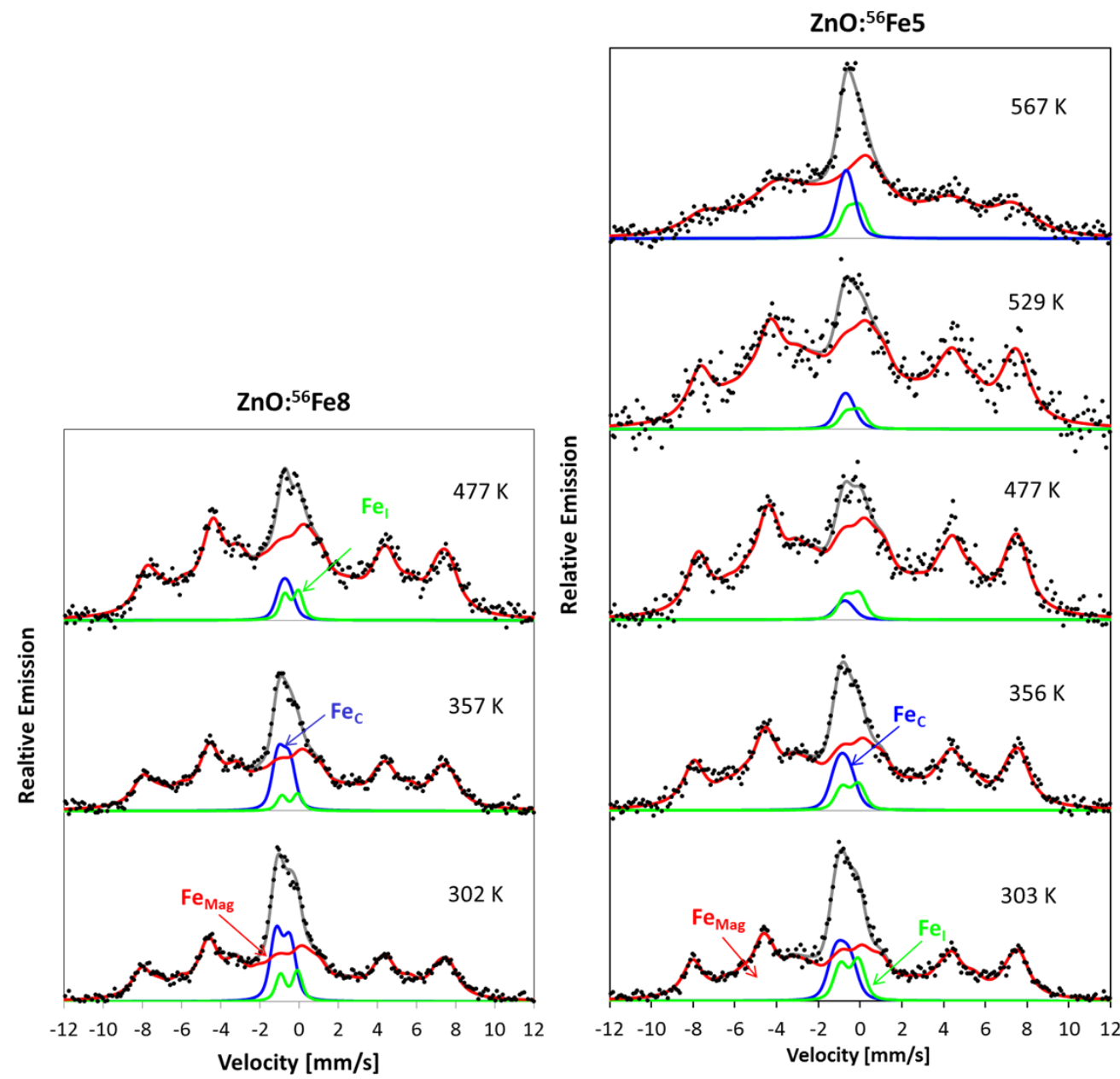

Figure 1: $\quad$ Emission Mössbauer spectra (eMS) of $\mathrm{ZnO}$ pre-implanted with ${ }^{56} \mathrm{Fe}$ at ion fluences (left) $8 \times 10^{13}$ and (right) $5 \times 10^{13}$ ions $/ \mathrm{cm}^{2}$ as a function of temperature.

The spectra were analysed using the Vinda program [11]. The analysis procedure and assignment of spectral components adopted here is similar to that applied in our earlier studies on virgin $\mathrm{ZnO}[8,9]$. The observed magnetic structure assigned to high-spin $\mathrm{Fe}^{3+}$ (labelled $\mathrm{Fe}_{\mathrm{Mag}}$ ) was analysed using the empirical model based on the Blume-Tjon (BT) [12] line-shape as described by Mølholt et al. [9, 13]. In the final fitting procedure, the magnetic feature was fitted 
with five BT sextets. This empirical model cannot determine the exact isomer shift or quadrupole splitting, but can determine the spin relaxation rates of $\mathrm{Fe}^{3+}$ and the maximum magnetic hyperfine splitting. The central regions of the spectra were fitted with two doublets attributed to $\mathrm{Fe}$ in the $2+$ state on regular crystalline sites $\left(\mathrm{Fe}_{\mathrm{C}}\right)$ and $\mathrm{Fe}$ on interstitial sites $\left(\mathrm{Fe}_{\mathrm{I}}\right)$ as described by Gunnlaugsson et al. [8]. The hyperfine parameters extracted at room temperature for all three samples are presented in Table 1.

Table 1: Room temperature hyperfine parameters extracted for $\mathrm{ZnO}$ pre-implanted with ${ }^{56} \mathrm{Fe}$ at indicated ion fluences.

\begin{tabular}{|c|c|c|c|c|c|c|}
\hline \multirow[b]{2}{*}{ Components } & \multicolumn{2}{|c|}{$\begin{array}{c}\mathrm{ZnO}:{ }^{56} \mathrm{Fe} 2 \\
\left(2 \times 10^{13} \text { ions } / \mathrm{cm}^{2}\right)\end{array}$} & \multicolumn{2}{|c|}{$\begin{array}{c}\mathrm{ZnO}:{ }^{56} \mathrm{Fe5} \\
\left(5 \times 10^{13} \text { ions } / \mathrm{cm}^{2}\right)\end{array}$} & \multicolumn{2}{|c|}{$\begin{array}{c}\mathrm{ZnO}:{ }^{56} \mathrm{Fe} 8 \\
\left(8 \times 10^{13} \mathrm{ions} / \mathrm{cm}^{2}\right)\end{array}$} \\
\hline & $\mathbf{F e c}$ & $\mathbf{F e}_{\mathbf{I}}$ & $\mathbf{F e c}$ & FeI & $\mathbf{F e c}$ & $\mathbf{F e}_{\mathbf{I}}$ \\
\hline$\delta(\mathbf{m m} / \mathbf{s})$ & $0.93(2)$ & $0.47(2)$ & $0.84(1)$ & $0.51(2)$ & $0.82(2)$ & $0.51(1)$ \\
\hline$\Delta E_{\mathrm{Q}}(\mathrm{mm} / \mathrm{s})$ & $-0.44(3)$ & $0.85(2)$ & $-0.66(3)$ & $0.85(1)$ & $-0.70(3)$ & $0.86(1)$ \\
\hline
\end{tabular}

The temperature dependence of the quadrupole splitting, $\Delta E_{\mathrm{Q}}(T)$ for $\mathrm{Fe}_{\mathrm{C}}$ was restricted to follow Ingalls [14] prediction as was followed in Gunnlaugsson et al. [15] and is given by the expression,

$$
\Delta E_{\mathrm{Q}}(T)=\Delta E_{\mathrm{Q}, \mathrm{Lat}}+\Delta E_{\mathrm{Q}, \mathrm{Val}} \tanh \left(\frac{E_{0}}{2 k_{\mathrm{B}} T}\right)
$$

where $\Delta E_{\mathrm{Q}, \text { Lat }}$ is the contribution from non-cubic arrangement of lattice atoms, $\Delta E_{\mathrm{Q}, \mathrm{Val}}$ is the valence contribution resulting from $\mathrm{Fe}$ in $z^{2} d$ orbitals, $E_{0}$ is the splitting energy between the $z^{2}$ and $x^{2}-y^{2}$ orbitals. A quadrupole splitting value of $-0.70(3) \mathrm{mm} / \mathrm{s}$ was obtained for $\mathrm{Fe}_{\mathrm{C}}$ and a crystal field splitting value of $E_{0}=18(1) \mathrm{meV}$ was determined for the high fluence implanted sample $\left(\mathrm{ZnO}:{ }^{56} \mathrm{Fe} 8\right)$ using $\Delta E_{\mathrm{Q}, \text { Lat }}$ and $\Delta E_{\mathrm{Q}, \text { Val }}$ values of $+0.12 \mathrm{~mm} / \mathrm{s}$ and $-2.5 \mathrm{~mm} / \mathrm{s}$, respectively, as reported by Gunnlaugsson et al. [15].

For the $\mathrm{ZnO}:{ }^{56} \mathrm{Fe} 5$ sample, a quadrupole splitting value of $-0.66(3) \mathrm{mm} / \mathrm{s}$ was determined for $\mathrm{Fe}_{\mathrm{C}}$ which is slightly smaller in magnitude compared with the value of $-0.70(3) \mathrm{mm} / \mathrm{s}$ obtained for the $\mathrm{ZnO}:{ }^{56} \mathrm{Fe} 8$ sample. The $E_{0}$ value for this sample was determined to be $17(1) \mathrm{meV}$. 
The $\mathrm{ZnO}:{ }^{56} \mathrm{Fe} 2$ sample was characterised with a $\Delta E_{\mathrm{Q}}$ value of $-0.44(2) \mathrm{mm} / \mathrm{s}$ for $\mathrm{Fe}_{\mathrm{C}}$ which is equivalent to the value of $-0.44(3) \mathrm{mm} / \mathrm{s}$ reported for virgin $\mathrm{ZnO}$ [8]. The resulting $E_{0}$ value of 12 (3) $\mathrm{meV}$ is comparable to the value of $10 \mathrm{meV}$ reported for virgin $\mathrm{ZnO}$ [9] considering the relative large error.

\section{Discussion}

The increase in the magnitude of the quadrupole splitting with increasing fluence suggests a loss of symmetry at the nucleus of the Fe atoms, resulting from an increase in lattice distortions with increasing implantation fluence. On the other hand, the decrease in the isomer shift values of $\mathrm{Fe}_{\mathrm{C}}$ with increasing implantation fluence reflects an increase in the $s$-electron density at the nucleus of the probe atoms which attests to the strengthening of the bonds between the substitutional Fe atoms and the surrounding lattice atoms. For the samples under study, the hyperfine parameters for the interstitial component $\left(\mathrm{Fe}_{\mathrm{I}}\right)$ are in agreement with values of $\delta=$ $0.50 \mathrm{~mm} / \mathrm{s}$ and $\Delta E_{\mathrm{Q}}=0.85 \mathrm{~mm} / \mathrm{s}$, reported in ref [8].

The relaxation rates are related to the temperature dependent line broadening $(\Delta \Gamma)$ of the sextets as described by Mølholt et al.[13]. Generally, it is expected that the spin lattice relaxation rate increases with increasing temperature because of the temperature dependence of the population of the phonon states [16]. The relaxation rates obtained from this study are shown in Figure 2 and are compared with those reported for virgin single crystal $\mathrm{ZnO}$ and $\alpha-\mathrm{Al}_{2} \mathrm{O}_{3}$ reported in ref [9].

A deviation from a $\sim T^{9}$ temperature dependence of the relaxation rates in virgin is observed. The data is consistent with additional spin-spin relaxation rates to the temperature dependent sin-lattice relaxation rates. These spin-spin interaction become dominant above when the concentration Fe ions is above 0.2 at.\% [10]. Thus, the three measured concentrations lie just below this threshold. 


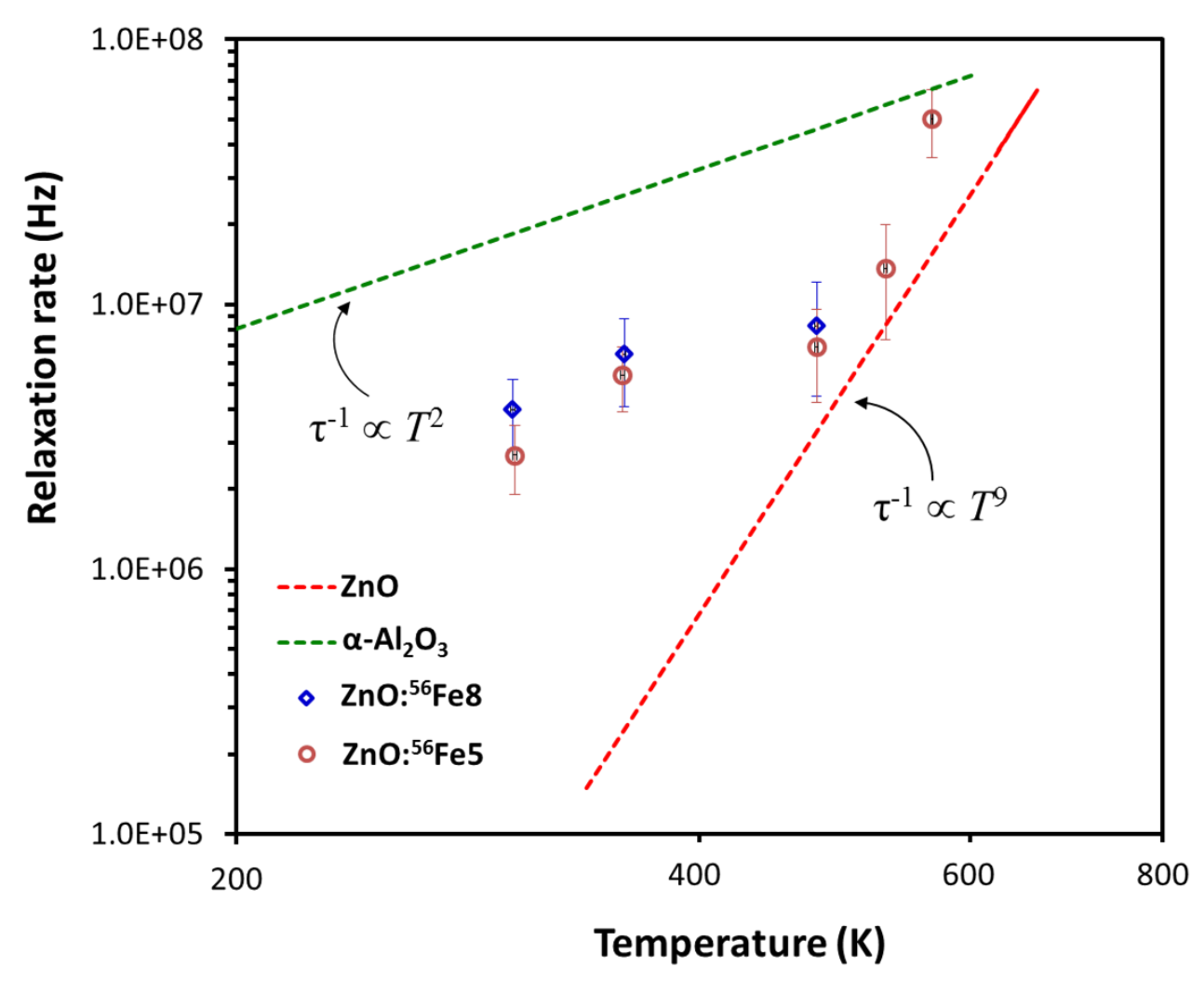

Figure 2: Temperature dependent relaxation rates of the pre-implanted $\mathrm{ZnO}$ samples as a function of indicated fluence compared with trends in virgin $\mathrm{ZnO}$ and $\alpha-\mathrm{Al}_{2} \mathrm{O}_{3}$. [Adapted from Mølholt et al. [9]]

The relaxation rates of the $\mathrm{ZnO}:{ }^{56} \mathrm{Fe} 5$ and ${ }^{56} \mathrm{Fe} 8$ pre-implanted samples shows slight tendency to increase with increasing fluence at equivalent temperatures. This may be attributed to the increase in spin density by the increasing Fe fluence, with a consequential increase in spinlattice relaxation rate. For the $\mathrm{ZnO}:{ }^{56} \mathrm{Fe} 8$ sample, the three temperatures show a trend which approximates a $T^{2}$ temperature-dependent relaxation rate which agrees with the measurements at equivalent temperatures for $\mathrm{ZnO}:{ }^{56} \mathrm{Fe} 5$. For $\mathrm{ZnO}:{ }^{56} \mathrm{Fe} 5$ there is deviation from this behaviour at highest temperature. This seems to suggest two different relaxation processes taking place in the measured temperature range for the $\mathrm{ZnO}:{ }^{56} \mathrm{Fe} 5$ sample. The spectra for the $2 \times 10^{13}$ ions $/ \mathrm{cm}^{2}\left(\mathrm{ZnO}:{ }^{56} \mathrm{Fe} 2\right)$ pre-implanted sample were unfortunately associated with additional broadening due to vibrations in the experimental set-up and hence could not be used to extract the relaxation rates but was sufficient to give the area fraction of the $\mathrm{Fe}^{3+}$ at room temperature. The area fractions extracted at room temperature for $\mathrm{Fe}^{3+}$ as a function of concentration, together with results obtained from earlier studies reported by Mantovan et al. [10], are presented in Figure 3. This investigation showed at low concentrations up to about $\sim 1.7 \times 10^{-4}$ at.\%, the fraction of $\mathrm{Fe}^{3+}$ steadily increases at the expense of $\mathrm{Fe}^{2+}$ reaching at maximum of 
approximately 80(3) \%. For the three samples studied here, no significant changes in spectral features are observed at $\mathrm{RT}$ and the area fraction of the magnetic component $\left(\mathrm{Fe}_{\mathrm{Mag}}\right)$ constitutes $\sim 80(3) \%$ of the spectral area. Figure 3 shows that $\mathrm{Fe}_{\mathrm{Mag}}$ reaches a flattened maximum at the fluences used in the present work suggesting that $\mathrm{Fe}^{3+}$ is stabilised in samples with concentrations in the range of $0.49 \times 10^{-2}-1.97 \times 10^{-2}$ at. $\%$. On the other hand, at concentrations above 0.02 at. $\%, \mathrm{Fe}^{2+}$ in the form of $\mathrm{Fe}_{\mathrm{C}}$ and $\mathrm{Fe}_{\mathrm{D}}$ (implantation-induced damage) dominates suggesting that $\mathrm{Fe}$-related donors dominate and in turn favour the formation of $\mathrm{Fe}^{2+}$ state over $\mathrm{Fe}^{3+}[10]$.

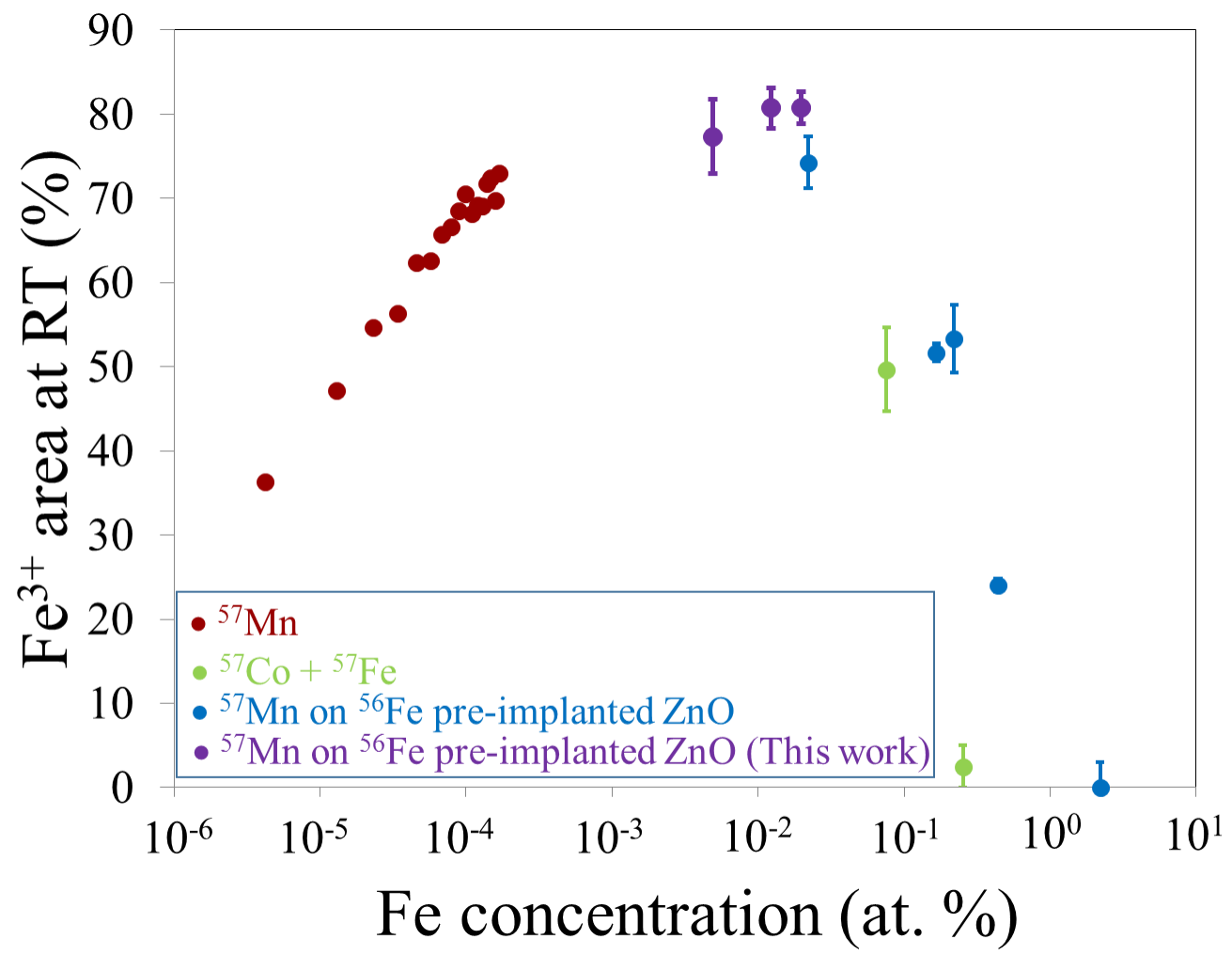

Figure 3: Concentration dependence of the area fraction of $\mathrm{Fe}^{3+}$ at room temperature. Results of the present measurements are included in the data adopted from ref. [10].

The results in Figure 3 indicate that the contribution of $\mathrm{Fe}^{3+}$ reaches a saturation for concentration in the range of $5 \times 10^{-3}$ to $5 \times 10^{-1}$ at. $\%\left(10^{12}-10^{14}\right.$ ions $\left./ \mathrm{cm}^{2}\right)$. For concentrations below $\sim 5 \times 10^{-3}$ at. $\%$, the $\mathrm{Fe}^{3+}$ state is unstable and the area fraction of the $\mathrm{Fe}^{3+}$ can be 'reset' by annealing of the $\mathrm{ZnO}$ sample, as reported by Naidoo et al. [17], while above a fluence of $10^{14}$ ions $/ \mathrm{cm}^{2}$, only $\mathrm{Fe}^{2+}$ dominates the eMS spectra. 


\section{Conclusions}

eMS measurements were conducted on three $\mathrm{ZnO}$ single crystal samples pre-implanted with ${ }^{56} \mathrm{Fe}$ to fluences of $2 \times 10^{13}, 5 \times 10^{13}$ and $8 \times 10^{13} \mathrm{ions} / \mathrm{cm}^{2}$. The spectra are dominated by magnetic features attributed to paramagnetic $\mathrm{Fe}^{3+}$ in defect complexes which show relatively long spinlattice relaxation times. Spin relaxation rates extracted from the analysis shows a relatively small increasing tendency with implanted fluence at corresponding temperatures. The area fraction of the paramagnetic $\mathrm{Fe}^{3+}$ shows a maximum contribution of approximately $80(3) \%$ of the spectra at room temperature for the three fluences.

\section{Acknowledgements}

This work was supported by the European Union Seventh Framework through ENSAR (contract no. 262010) and the German BMBF under Contract No. 05KK4TS1/9. H. Masenda, K. Bharuth-Ram, D. Naidoo and M. Ncube acknowledge support from the South African National Research Foundation and the Department of Science and Technology within the SACERN programme. T. E. Mølholt, S. Shayestehaminzadeh, H. P. Gíslason and S. Ólafsson support from the Icelandic Research Fund. We acknowledge support from the Deutsche Forschungsgemeinschaft (Ro1198/13-1). R. Mantovan acknowledges support from MIUR through the FIRB Project RBAP115AYN "Oxides at the nanoscale: multifunctionality and applications".

\section{References}

[1] C. Liu, F. Yun and H. Morkoç, J. Mater. Sci. Mater. Electron., vol. 16, p. 555, 2005.

[2] Ü. Özgür, Y. I. Alivov, C. Liu, A. Teke, M. A. Reshchikov, S. Doğan, V. Avrutin, S.-J. Cho and H. Morkoç, J. Appl. Phys., vol. 98, p. 041301, 2005.

[3] K. Ando, Science, vol. 312, p. 1883, 2006.

[4] V. Avrutin, N. Izyumskay, U. Ozgur, D. J. Silversmith and H. Morkoc, Proc. IEEE, vol. 98, p. 1288, 2010.

[5] T. Dietl, Nature. Mater., vol. 9, p. 965, 2010.

[6] A. Zunger, S. Lany and H. Raebiger, Physics, vol. 3, p. 53, 2010.

[7] L. Pereira, J. Araujo, U. Wahl, S. Decoster, M. Van Bael, K. Temst and A. Vantomme, J. Appl. Phys., vol. 113, p. 023903, 2013. 
[8] H. P. Gunnlaugsson, T. E. Mølholt, R. Mantovan, H. Masenda, D. Naidoo, W. B. Dlamini, R. Sielemann, K. Bharuth-Ram, G. Weyer, K. Johnston, G. Langouche, S. Ólafsson, H. P. Gíslason, Y. Kobayashi, Y. Yoshida, M. Fanciulli and the ISOLDE Collaboration, Appl. Phys. Lett., vol. 97, p. 142501, 2010.

[9] T. E. Mølholt, H. P. Gunnlaugsson, K. Johnston, R. Mantovan, H. Masenda, D. Naidoo, S. Ólafsson, K. Bharuth-Ram, H. P. Gislason, G. Langouche, R. Sielemann, G. Weyer and t. I. Collaboration, Phys. Scr., vol. T148, p. 014006, 2012.

[10] R. Mantovan, H. P. Gunnlaugsson, K. Johnston, H. Masenda, T. E. Mølholt, D. Naidoo, M. Ncube, S. Shayestehaminzadeh, K. Bharuth-Ram, M. Fanciulli, H. P. Gíslason, G. Langouche, S. Ólafsson, L. M. C. Pereira, U. Wahl, P. Torelli and G. Weyer, Adv. Electron. Mater., vol. 1, p. 1400039, 2015.

[11] H. P. Gunnlaugsson, Hyp. Int., 2015 (Accepted).

[12] M. Blume and J. A. Tjon, Phys. Rev., vol. 165, p. 446, 1968.

[13] T. E. Mølholt, R. Mantovan, H. P. Gunnlaugsson, D. Naidoo, S. Ólafsson, K. BharuthRam, M. Fanciulli, K. Johnston, Y. Kobayashi, G. Langouche, H. Masenda, R. Sielemann, G. Weyer and H. P. Gíslason, Hyp. Int. , vol. 197, p. 89, 2010.

[14] R. Ingalls, Phys. Rev., vol. 133, p. A787, 1964.

[15] H. P. Gunnlaugsson, K. Johnston, T. E. Mølholt, G. Weyer, R. Mantovan, H. Masenda, D. Naidoo, S. Ólafsson, K. Bharuth-Ram, H. P. Gíslason, G. Langouche, M. B. Masden and t. I. Collab, Appl. Phys. Lett., vol. 100, p. 042109, 2012.

[16] S. Mørup, in Mössbauer Spectroscopy and Transition Metal Chemistry: Fundamentals and Application, P. Gütlich, E. Bill and A. X. Trautwein, Eds., Berlin, Springer, 2010.

[17] P. Raj and S. K. Kulshreshtha, Phys. Stat. Sol. (A), vol. 4, p. 501, 1971.

[18] D. Naidoo, H. P. Gunnlaugsson, T. E. Mølholt, R. Mantovan, H. Masenda, K. BharuthRam, K. Johnston, H. P. Gislason, G. Langouche and S. Ólafsson, Hyp. Int., vol. 221, p. 45, 2013. 